\title{
Neuroprotective Effects Of The Inert Gas Argon Onexperimental Traumatic Brain Injury In Vivo With The Controlled Cortical Impact Model In Mice
}

\section{Fritz I. Schneider}

Technische Universitat Munchen Fakultat fur Medizin

\section{Sandro M Krieg ( $D$ Sandro.Krieg@tum.de)}

Klinikum rechts der Isar der Technischen Universitat Munchen https://orcid.org/0000-0003-4050-1531

Ute Lindauer

Universitatsklinikum Aachen

Michael Stoffel

HELIOS Klinikum Krefeld

Yu-Mi Ryang

Technische Universitat Munchen Fakultat fur Medizin

Research article

Keywords: Experimental TBI (Traumatic Brain Injury), Argon, Inert Gases, Neurological Outcome, Brain Contusion Volume, Brain Edema Volume, Intracranial Pressure (ICP), Cerebral Blood Flow (CBF)

Posted Date: January 20th, 2021

DOI: https://doi.org/10.21203/rs.3.rs-62320/v1

License: (c) (1) This work is licensed under a Creative Commons Attribution 4.0 International License. Read Full License 


\section{Abstract}

BACKGROUND: Argon has shown neuroprotective effects after traumatic brain injury (TBI) and cerebral ischemia in vitro and in focal cerebral ischemia in vivo. The purpose of this study is to show if Argon beneficially impacts brain contusion volume (BCV) as the primary outcome parameter as well as secondary outcome parameters such as brain edema, intracranial pressure (ICP), neurological outcome, and cerebral blood flow (CBF) in an in vivo model.

METHODS: Subjects were randomly assigned to either argon treatment or room air. After applying controlled cortical impact (CCl) onto the dura with $8 \mathrm{~m} / \mathrm{s}$ (displacement $1 \mathrm{~mm}$, impact duration $150 \mathrm{~ms}$ ), treatment was administered by a recovery chamber with $25 \%, 50 \%$, or $75 \%$ argon and the rest being oxygen for $4 \mathrm{~h}$ after trauma. Two control groups received room air for $15 \mathrm{~min}$ and $24 \mathrm{~h}$, respectively. Neurological testing and ICP measurements were performed $24 \mathrm{~h}$ after trauma, and brains were removed to measure secondary brain damage.

RESULTS: The primary outcome parameter BCV and the secondary outcome parameter brain edema were not significantly reduced by argon treatment at any concentration, respectively. There was a highly significant decrease in ICP at 50\% argon ( $\mathrm{p}=0.001)$, and significant neurological improvement (beamwalk missteps) at $25 \%$ and $50 \%$ argon ( $p=0.01 ; p=0.049$ respectively) compared to control.

CONCLUSIONS: Similar to prior in vitro studies argon exerts its best neuroprotective effects with regard to neurological outcome and ICP at a concentration of $50 \%$. Furthermore, a significant improvement in neurological outcome was observed at an argon concentration of $25 \%$. There was no significant reduction of $\mathrm{BCV}$ as the primary outcome parameter.

\section{Background}

Secondary brain damage emerges as a result of ischemia, excitotoxic events, brain edema, rising intracranial pressure (ICP), blood-brain barrier leakage, low systemic blood pressure, and hypoxia in the course of minutes to days after trauma [1,2]. Today's therapeutic options focus on reducing the extent of secondary brain damage and thus improving neurological outcome. However, there is no established therapy that specifically targets preventing apoptosis of endangered cells in the penumbra [3].

Argon has shown several promising neuroprotective properties despite being chemically inert. Argon has shown significant reduction of neuronal cell death in vitro after mechanical trauma and glucose/oxygen deprivation [3, 4]. Moreover, in vivo studies showed protection against excitotoxic stress, i.e. NMDAinjections, and focal ischemia after middle cerebral artery occlusion (MCAO) in rats $[4,5]$. The mechanism of neuroprotection mediated by argon remains unclear. Recently, a whole string of possible candidates is being discussed involving hydrophobic interactions at protein cavities leading to altered gene expression via the ERK (Extracellular Signal-Regulated Kinase) 1/2 pathway, modification of enzymes like tissue plasminogen activator (tPA) [6-9]. In contrast,other studies have found an increase in inflammatory mediators after argon treatment following in vivo ischemia in rats [10]. 
This study aims to examine argon in an in vivo model of TBI (controlled cortical impact, $\mathrm{CCl}$ ) and at determining the optimal length, concentration, and timing of posttraumatic argon treatment. The three applied argon concentrations are based on the results of an in vitro TBI study [3]. Additionally, the systemic effects of argon were investigated.

The primary outcome parameter was brain contusion volume $24 \mathrm{~h}$ after TBI. Additionally, we measured intracranial pressure, neurological outcome and brain water content $24 \mathrm{~h}$ after trauma as secondary outcome parameters.

\section{Material And Methods \\ 2.1 Animals}

Male C57BI/6 mice (20-22 g) were obtained from a commercial breeder of laboratory animals (Charles River Laboratories, Sulzfeld, Germany). Animals were kept in Makrolon cages in a controlled environment $\left(22.0^{\circ} \mathrm{C} / 55 \%\right.$ humidity) and had free access to food and water before and during the experimental phase. Day/night cycles were kept constant with lighting from 8 a.m. to 8 p.m. After the experiments, all animals were anesthetized and sacrificed by cervical dislocation under deep anesthesia.

\section{$2.2 \quad \mathrm{CCl}$}

We used the widely established $\mathrm{CCI}[11,12]$. For analgesia i.p. injections of buprenorphine were applied ( $0.1 \mathrm{mg}$ per $\mathrm{kg}$ bodyweight; $\mathrm{mg} / \mathrm{kg} \mathrm{BW}$ ). Animals were put in short isoflurane anesthesia (4-5\%vol for induction, $1-2 \%$ to maintain) with $30 \% \mathrm{O}_{2}$ and $70 \% \mathrm{~N}_{2} \mathrm{O}$ via facemask. Craniotomy of the right temporal bone was performed under preservation of the dura above the motor cortex. The size of the craniotomy was approximately $5 \times 5 \mathrm{~mm}$. CCI (Mouse-Katjuscha 2000, L. Kopacz, University of Mainz, Germany)[13, 14] was as follows: diameter of the impact tip $3 \mathrm{~mm}$; impact velocity $8 \mathrm{~m} / \mathrm{s}$; duration $150 \mathrm{~ms}$. The bone flap was then placed back and affixed with histoacryl glue (Braun-Melsungen, Melsungen, Germany). The duration of the surgical procedure did not exceed 15 minutes.

\subsection{Study Protocol}

Blinding was performed by laboratory personnel who randomly presented the animals to the examiner for surgery and testing. Blinding was dissolved only after the complete assessment of the respective test series. Confounders were not controlled, as the procedure did not vary for each animal.

All groups consisted of 10 animals. A total number of 210 animals were examined in all test series. In the further explanations, the number of animals included in the statistical analysis is shown in tabular form. Only animals that died in the course of the experiments or for which the evaluation was not possible due to technical difficulties were excluded. 
Sample sizes in this orientational study were based on previous experiments with this damage model and argon treatment.

\section{Test Series: Optimal Argon Concentration}

Argon administration at defined concentrations 30 min prior to trauma and continued for $4 \mathrm{~h}$ after trauma. The purpose of this very first test series was to measure neuroprotection under optimal circumstances, i.e. administering argon before trauma to ensure optimal brain tissue concentrations although these conditions are unlikely in a clinical setting. All argon was supplied by a commercial producer with a purity level above 99.9\% (SWF, Sauerstoffwerk Friedrichshafen, Friedrichshafen, Germany). Medical grade oxygen, nitrogen, and nitrous oxide were readily available in our laboratory.

Control group is exposed to room air for the entire duration of test series 1. All animals were placed in heated, semi-open boxes at a constant temperature of 26 degrees Celsius. For all test series, oxygen and argon levels were continuously monitored during treatment with an oxygen (Dräger Oxydig, Dräger, Lübeck, Germany) and argon meter (Servopro Monoexact, Servomex, Hamm, Deutschland). A continuous fresh gas flow of at least 0.1 I was established with a custom, calibrated flowmeter for oxygen, nitrogen, and argon, leading to a complete exchange of gas in the box within less than 15 minutes. The temperature in the boxes was fixed at $26^{\circ} \mathrm{C}$.

Brain Contusion Volumes (BCV):

15-min survival: $\quad$-no therapy (room air) $\quad n=10$

24-h survival: $\quad$-no therapy (room air) $n=10$

$$
\begin{array}{ll}
-25 \% \mathrm{Ar} / 75 \% \mathrm{O}_{2} & \mathrm{n}=8 \\
-50 \% \mathrm{Ar} / 50 \% \mathrm{O}_{2} & \mathrm{n}=10 \\
-75 \% \mathrm{Ar} / 25 \% \mathrm{O}_{2} & \mathrm{n}=9
\end{array}
$$

Brain Water Content (BWC) and ICP

24-h survival: $\quad$-no therapy (room air) $n=9$

$$
\begin{array}{ll}
-25 \% \mathrm{Ar} / 75 \% \mathrm{O}_{2} & \mathrm{n}=9 \\
-50 \% \mathrm{Ar} / 50 \% \mathrm{O}_{2} & \mathrm{n}=10 \\
-75 \% \mathrm{Ar} / 25 \% \mathrm{O}_{2} & \mathrm{n}=9
\end{array}
$$


Utilizing the determined optimal argon concentration assessment of the optimal duration of argon application with two sub-test series follows. Start of argon 30 min before CCl. 50\% argon / 50\% oxygen in the therapeutic group corresponding to results of prior in vitro experiments and to our own findings in the first test series were used [3]. Control animals received room air. Moreover, an oxygen control group treated with $50 \%$ oxygen / $50 \%$ nitrogen was done.

BCV:

24-h survival: $\quad$-no therapy (room air) $\quad n=9$

$$
\begin{array}{ll}
\text {-oxygen / nitrogen } 24 \mathrm{~h} \text { treatment } & \mathrm{n}=9 \\
\text {-oxygen / argon 24h treatment } & \mathrm{n}=10
\end{array}
$$

BWC and ICP

24-h survival: $\quad$-no therapy (room air) $\quad n=8$

-oxygen / nitrogen $24 \mathrm{~h}$ treatment $\quad \mathrm{n}=8$

-oxygen / argon 24h treatment $\quad n=9$

3. Test Series: Treatment at Physiological Oxygen Levels

This series was introduced to eliminate any interference that might occur because of elevated oxygen levels. Control animals received $20 \%$ oxygen and $80 \%$ nitrogen. The animals treated with argon received $20 \%$ oxygen, $50 \%$ argon, and $30 \%$ nitrogen. Start of therapy $30 \mathrm{~min}$ before and $24 \mathrm{~h}$ after $\mathrm{CCl}$ in both subgroups.

BCV:

24-h survival: $\quad$-no therapy $\quad n=7$ -argon $24 \mathrm{~h}$ treatment $\mathrm{n}=9$

BWC and ICP:

24-h survival: $\quad$ no therapy $\quad n=10$

-argon $24 \mathrm{~h}$ treatment $\mathrm{n}=8$ 
4. Test Series: Effects of Argon on MAP and CBF after CCI

After determining the optimal concentration of argon, we analyzed MAP and CBF 30 min before, until $2 \mathrm{~h}$ after $\mathrm{CCl}$. Argon therapy or $\mathrm{O}_{2} / \mathrm{N}_{2}$ was administered at the same time period, when applicable.

BCV:

$$
\begin{array}{lll}
\text { 2-h survival: } & -50 \% \mathrm{O}_{2} / 50 \% \mathrm{~N}_{2} & \mathrm{n}=8 \\
& -50 \% \mathrm{Ar} / 50 \% \mathrm{O}_{2} & \mathrm{n}=10
\end{array}
$$

\subsection{Neuroscores and Beamwalk Testing}

Neurological status was assessed $24 \mathrm{~h}$ after trauma after a modified Dixon's and Bederson's neuroscore (table 1) [15-17]. Mice underwent beamwalk testing, crossing a $40 \mathrm{~cm}$ long non-slip beam (diameter 1.5 $\mathrm{cm}$ ) three times; missteps of the left leg were counted during that procedure.

\subsection{Histology and BCV}

After sacrificing the animals assigned for BCV measurement (after $24 \mathrm{~h}$, exception: 15-min controls) through cervical dislocation in deep isoflurane anesthesia, brains were removed and frozen at $-70^{\circ} \mathrm{C}$. Coronal slices were prepared with a cryostat. $10 \mu \mathrm{m}$ coronal slices were collected with an interslice thickness of $500 \mu \mathrm{m}$ throughout the entire brain. Slices were H\&E (hematoxylin and eosin)-stained and contusion areas $a_{n}$ for each slice were measured, $n$ being the number of slices, using a digital image analyzing software and microscope (Olympus Cell Sense, Olympus Lifescience, Hamburg, Germany). BCV was calculated using the formula

$\mathrm{V}_{\text {Contusion }} / \mathrm{mm}^{3}=\left(\mathrm{a}_{1}+\mathrm{a}_{2}+\mathrm{a}_{3}+\cdots+\mathrm{a}_{\mathrm{n}}\right) \star 0.5 \mathrm{~mm}$.

\subsection{BWC and ICP Measurement}

All animals assigned for ICP and BWC were put in short inhalative anesthesia $24 \mathrm{~h}$ after CCI. Contralateral to the trauma side, the temporal muscle was mobilized by blunt preparation and a small trephination was performed in the lateral temporal bone. An ICP microsensor (CP Express, Codman Neuro, Raynham, MA, USA) was inserted in the epidural space of the contralateral hemisphere after being calibrated in distilled water. After $5 \mathrm{~min}$ the ICP value was registered. Brains were promptly removed, cerebellum and olfactory 
bulbs removed and hemispheres divided. They were then measured wet $\left(\mathrm{W}_{\mathrm{Wet}}\right)$ and again after drying for $24 \mathrm{~h}$ at $90^{\circ} \mathrm{C}\left(\mathrm{W}_{\text {Dry }}\right)$. BWC of the hemispheres was then determined via:

$\mathrm{P}_{\text {Water }}=\left(\mathrm{W}_{\text {Wet }}-\mathrm{W}_{\text {Dry }}\right) / \mathrm{W}_{\text {Wet }}$

\subsection{MAP and CBF measurement}

For this study 18 mice were anesthetized with intraperitoneal injections of medetomidine, midazolam, and fentanyl. As the experiments had to last at least 2.5 hours mice were intubated and mechanically ventilated (MiniVent 845, Hugo Sachs Elektronik, March-Hugstetten, Germany). Gas concentrations were $50 \%$ oxygen and $50 \%$ nitrogen for all animals prior to $\mathrm{CCl}$. In order to ensure appropriate ventilation, arterial blood gas analyses were taken at regular intervals (after 0 , 30, 90, $150 \mathrm{~min}$ ).

In order to monitor MAP the femoral arteries were dissected and a fluid filled catheter inserted into the femoral artery and the pressure measured by a manometer (Pressure Monitor BP-1, World Precision Instruments, Sarasota, Florida, USA). To control the cerebral blood flow the right temporal muscle was detached from the skull with a scalpel. The laser Doppler probe (Periflux 5000, Perimed, Järfälla, Sweden) was then fixated directly on the skull. All data were automatically recorded and saved at $1 \mathrm{Hertz}$ via computer interfaces (Labscribe 2, iWorx, Dover, NH, USA). CCI was performed as stated above.

MAP and cerebral blood flow were recorded for 30 minutes prior to $\mathrm{CCl}$ in order to have baseline values for all animals. After $\mathrm{CCl}, 8$ control-group animals continued to receive $50 \%$ oxygen and $50 \%$ nitrogen, whereas 10 argon-treated mice received $50 \%$ argon and $50 \%$ oxygen. Treatment was performed for two hours with continuous monitoring of MAP and CBF. Afterwards the mice were sacrificed. We refrained from assessing these animals neurologically due to limited validity after long anesthesia.

\subsection{Statistical Analysis}

Statistical work was performed with SPSS 22 (IBM, Ehningen, Germany). ANOVA with an unpaired t-test analysis was used for ICP, BWC, BCV, and beamwalk testing. For neuroscores a Mann-Whitney-U test was used. All results are displayed as mean value \pm standard deviation (SD).

\section{Results}

\section{1 \\ 1st Test Series: Optimal Argon Concentration}

No animals died during treatment.

Primary Brain Damage 
$\mathrm{BCV}$ in the 15-min control group, representing primary damage after $\mathrm{CCl}$ were $10.5 \pm 1.1 \mathrm{~mm}^{3}$. Compared with the $24 \mathrm{~h}$ control group $\left(19.4 \pm 3.2 \mathrm{~mm}^{3}\right)$, there was a mean growth of BCV by $8.9 \mathrm{~mm}^{3}(85 \%$ of primary BCV $)(p<0.001)$ due to secondary brain damage.

\section{Effect of Argon on BCV}

There were no significant differences in BCV in all groups (Figure 1).

Effect of Argon on ICP and BWC

ICP directly before removal of the brains showed mean ICP values of $44.9 \pm 6.4 \mathrm{mmHg}$ (24-h control), $42.3 \pm 3.6 \mathrm{mmHg}(25 \%$ argon, $p=0.31), 29.5 \pm 6.2 \mathrm{mmHg}(50 \%$ argon, $p<0.001)$, and $39.2 \pm 8.9 \mathrm{mmHg}$ (75\% argon, $p=0.13)$ (Figure 1$)$.

Mean BWC in the ipsilateral hemispheres were as follows: $80.72 \pm 0.98 \%$ ( $24 \mathrm{~h}$ control), $81.27 \pm 0.35 \%$ (25\% argon, $p=0.13), 81.03 \pm 0.53 \%$ (50\% argon, $p=0.40)$, and $81.40 \pm 0.47 \%$ (75\% argon, $p=0.65)$. There was significant increase in BWC due to trauma in all groups in the ipsilateral hemispheres $(p<0.001)$ compared to the contralateral hemispheres (Figure 1). Mean BWC in the contralateral hemispheres did not differ significantly (Figure 1).

Neurological Outcome and Beamwalk Test

Beamwalk was assessed $24 \mathrm{~h}$ after $\mathrm{CCl}$ for all animals except the 15 -min control. Cumulative numbers of missteps in 3 walks were $5.8 \pm 3.1$ ( $24 \mathrm{~h}$ control), $5.2 \pm 3.8$ ( $25 \%$ argon, $p=0.56), 2.8 \pm 2.2$ (50\% argon, $p=0.001)$, and $4.2 \pm 3.3(75 \%$ argon, $p=0.14)$. There was a significant reduction of missteps in the group treated with $50 \%$ argon $(p=0.001)$ compared to the control group (Figure 2$)$.

Neuroscores were obtained at the same time as the beamwalking test. The scores were $2.1 \pm 0.7$ (24 h control), $1.47 \pm 0.6(25 \%$ argon, $p=0.01), 1.7 \pm 0.8$ (50\% argon, $p=0.049)$, and $1.8 \pm 0.6$ (75\% argon, $p=0.21)$. There was a significant improvement in neuroscores in animals treated with $25 \%(p=0.01)$ and $50 \%$ argon $(p=0.049)$ when compared to controls (Figure 2 ).

\subsection{2nd Test Series: Optimal Duration of Treatment}

Each group contained 19 animals for analysis. One animal of the room air control group and one of the argon-treated group died during treatment, approximately $30 \mathrm{~min}$ and $6 \mathrm{~h}$ after trauma, respectively. One animal of the oxygen control group died before trauma during preparation of the craniotomy.

Effect of Argon on BCV

BCV was determined as above mentioned after $24 \mathrm{~h}$. There were three groups. Mean BCV were $21.6 \pm 2.4$ $\mathrm{mm}^{3}$ (room air control), $21.7 \pm 4.0 \mathrm{~mm}^{3}$ (control group, oxygen), and $19.7 \pm 3.4 \mathrm{~mm}^{3}$ (argon treatment), respectively (n.s.). 
ICP measurements after $24 \mathrm{~h}$ were as follows: $45.4 \pm 9.3 \mathrm{mmHg}$ (room air control group), $47.4 \pm 5.7$ $\mathrm{mmHg}$ (oxygen control group), and $42.4 \pm 4.4 \mathrm{mmHg}$ (argon treatment) (n.s.). BWC in the ipsilateral hemispheres after $24 \mathrm{~h}$ showed percentages of $81.0 \pm 0.7 \%$ (room air control group), $81.1 \pm 0.4 \%$ (oxygen control group), and $80.8 \pm 0.6 \%$ (argon treatment) (n.s.). BWC in the contralateral hemispheres were 79.0 $\pm 0.4 \%$ (room air control group), $78.9 \pm 0.4 \%$ (oxygen control group), and $78.8 \pm 0.4 \%$ (argon treatment), respectively (n.s.).. There was a highly significant $(p<0.001)$ difference in BWC when comparing ipsilateral and contralateral hemispheres in all groups.

Neurological Outcome and Beamwalk Test

The number of missteps in beamwalk tests did not show any significant difference when comparing argon treatment $(3.0 \pm 4.3)$ with room air control $(4.0 \pm 2.2)(p=0.36)$ and oxygen control $(5.16 \pm 2.9)$ $(p=0.08)$. The neuroscores of argon treated mice $(1.7 \pm 0.6)$ improved significantly when compared to oxygen control animals $(2.5 \pm 0.7)(p=0.001)$, while there was no significant change when compared to room air controls $(1.9 \pm 0.7)(p=0.37)$.

\subsection{3rd Test Series: Treatment at Physiological Oxygen Levels}

The introduction of an oxygen control group has shown us worse outcomes for animals that received $50 \%$ oxygen and $50 \%$ nitrogen. Although not significant, the difference between oxygen control and argon treatment prompted us to introduce a test series in which we set oxygen at $20 \% .17$ animals were included in the analysis in each group. 6 subjects were excluded because of methodical reasons of failed recording. No animal died.

\section{Effect of Argon on BCV}

There was no significant difference in mean BCV after $24 \mathrm{~h}$ when comparing argon treated mice (25.6 \pm $\left.3.1 \mathrm{~mm}^{3}\right)$ with control mice $\left(27.3 \pm 1.5 \mathrm{~mm}^{3}\right)(p=0.19)$.

Effect of Argon on ICP and BWC

There was no significant difference in mean ICP after $24 \mathrm{~h}$ when comparing argon treated animals (43.7 $\pm 8.3 \mathrm{mmHg})$ with the control group $(47.6 \pm 8.0 \mathrm{mmHg})(\mathrm{p}=0.30)$. In the ipsilateral hemispheres BWC after $24 \mathrm{~h}$ was $81.3 \pm 0.5 \%$ for argon treatment and $81.3 \pm 0.4 \%$ for controls (n.s.) BWC in the contralateral hemispheres showed no significant difference between argon treatment $(79.0 \pm 0.4 \%)$ and control $(79.0 \pm$ $0.3 \%)(p=0.78)$.

There was a highly significant $(\mathrm{p}<0.001)$ difference between ipsilateral and contralateral hemispheres in both groups in BWC. 
Neurological Outcome and Beamwalk Test

There was no significant difference when comparing neuroscores of argon treatment $(2.4 \pm 0.8)$ and control $(2.1 \pm 0.9)(p=0.40)$. Moreover, there was no significant difference between argon treatment $(6.2 \pm$ $3.6)$ and control $(5.3 \pm 3.2)(p=0.41)$.

\subsection{4th Test Series: Effects of argon on MAP and CBF after $\mathrm{CCl}$}

When comparing the mean values between argon treatment and controls, there was no significant difference in mean CBF (all $p$-values at $p=0.53$ or above) and MAP (all $p$-values at $p=0.46$ or above) during each interval for the entire recorded period of time (Figures $3 \& 4$ ).

\section{Discussion}

The results suggest a certain neuroprotective effect, namely at a functional level and at lowering ICP. However, these results have to be considered with caution.

There has been no significant reduction of BCV. If at all, we could observe a slight increase of BCV in all groups treated with argon compared to controls. Moreover, BWC of both hemispheres were at almost identical levels in all groups. Somewhat contradictory to these results is the observed reduction of ICP in mice treated with $50 \%$ argon. Likewise, the improved functional outcome in mice treated with $25 \%$ and $50 \%$ argon seem to have to no correlate in the other findings. We suspect that an inhibition of apoptosis leads to an increased number of neurons within the contused tissue and therefore to a better outcome. This could be shown in Loetscher's in vitro model of TBI and OGD where propidium iodide staining was used to identify necrotic cells [3]. The most effective concentration was 50\% in TBI. However, slices were incubated for $72 \mathrm{~h}$ as opposed to the $4 \mathrm{~h}$ we used. A similar study has also shown in vitro neuroprotection of argon in OGD after $24 \mathrm{~h}$ of incubation [18].

Several studies suggest a mechanism of action not involving ion channels. Argon is capable of inducing heat shock proteins via activation of ERK1/2, increasing Bcl-2 expression, increasing expression of inflammatory markers, inhibiting apoptotic proteins like caspase-3, and modifying tPA activity [7-10, 19, 20].

The ERK1/2 pathway is essential in regulation of cell cycle and apoptosis. It has significant importance in oncological studies as defects might lead to uncontrolled activation and therefore uncontrolled growth of tumors.

The antiapoptotic and neuroprotective effect by argon shown via ERK1/2 itself is mediated by decrease of density and expression of TLR (toll-like-receptor) 2 and 4 after rotenone induced cell damage. 
Moreover, argon's effect can be attenuated by administering inhibitors of the ERK1/2 and TLR pathway [21].

In an in vivo models of stroke, i.e. middle cerebral artery occlusion (MCAO), 50\% argon has turned out to reduce total infarct volume and functional outcome after $2 \mathrm{~h}$ of ischemic trauma in rats [5]. In this study, rats were administered $50 \%$ argon and $50 \%$ oxygen via facemask for $1 \mathrm{~h}$ after middle cerebral artery occlusion, i.e. intraischemic.

Another study found neuroprotective properties of argon when given in vitro after OGD [4]. The same study has shown neuroprotection after intra-striatal injection of NMDA in vivo in rats.

NMDA receptors are an important mediator in the development of secondary brain damage, leading to higher intracellular ion influx after massive glutamate release due to widespread depolarization of neurons and consecutive cellular swelling and cell death, hence excitotoxicity [22]. Xenon, another noble gas, has already shown neuroprotection by modifying the glycin-receptor site of NMDA-channels. However, argon does not seem to work through the same mechanism of action [23]. ATP-dependent potassium channels have also been ruled out in another in vivo study [24]. A potentiation of GABA receptors due to argon is under discussion [25].

Summarizing all findings of this and former studies, we can assume neuroprotective properties of argon when administered in vivo after $\mathrm{CCl}$ in mice through inhibition of apoptosis. However, the lack of reduction of BCV and BWC require further studies. This does particularly involve extension of treatment durations as argon was applied for $72 \mathrm{~h}$ in the only study that has shown neuroprotection after (in vitro) TBI. Additionally, as latest research suggests that argon does not target ion channels but modifies gene expression, a longer treatment duration might enhance these mechanisms and improve results. If the ERK1/2 pathway is indeed the main course of action supplementary drug intervention may further facilitate and enhance antiapoptotic effects $[10,21,23,26]$.

\section{Conclusions}

In summary, argon exerts neuroprotection mainly regarding functional outcome and to a lesser extent ICP. There is no effect on BCV, BWC, MAP, and CBF. Being efficient in improving functional outcome, argon has the potential to be used as an additional option besides established anti-edematous therapies. However, it has to be taken into consideration that the control group in the first test series received different oxygen levels weakening the informative value of the significant results in this series. More experiments regarding the involved molecular pathways are needed to confirm inhibition of apoptosis and the underlying mechanisms.

\section{List Of Abbreviations}

BCV Brain Contusion Volume 
BWC Brain Water Content

CBF Cerebral Blood Flow

CCl Controlled Cortical Impact

ICP Intracranial Pressure

MAP Mean Arterial Pressure

MCAO Middle Cerebral Artery Occlusion

TBI Traumatic Brain Injury

\section{Declarations}

\subsection{Ethics approval and consent to participate}

All animal experiments were registered and conducted with the approval of the Government of Upper Bavaria.

\subsection{Consent for publication}

Not applicable

\subsection{Availability of data and materials}

The datasets used and/or analysed during the current study are available from the corresponding author on reasonable request.

\subsection{Competing interests}

The authors declare that they have no competing interests.

\subsection{Funding}

The study was funded by the department for neurosurgery at the university hospital Klinikum Rechts der Isar in Munich of the Technical University Munich.

\subsection{Authors' contributions}


FS performed all experimental procedures including surgery, treatment, and analysis as described above and was a major contributor to the manuscript. The other authors contributed to the planning and practical implementation of the experiments.

\subsection{Acknowledgements}

Not applicable.

\section{References}

1. Golding EM, Robertson CS, Bryan RM, Jr.: The consequences of traumatic brain injury on cerebral blood flow and autoregulation: a review. Clin Exp Hypertens 1999, 21(4):299-332.

2. Teasdale GM, Pettigrew LE, Wilson JT, Murray G, Jennett B: Analyzing outcome of treatment of severe head injury: a review and update on advancing the use of the Glasgow Outcome Scale. $J$ Neurotrauma 1998, 15(8):587-597.

3. Loetscher PD, Rossaint J, Rossaint R, Weis J, Fries M, Fahlenkamp A, Ryang YM, Grottke O, Coburn $\mathrm{M}$ : Argon: neuroprotection in in vitro models of cerebral ischemia and traumatic brain injury. Crit Care 2009, 13(6):R206.

4. David HN, Haelewyn B, Degoulet M, Colomb DG, Jr., Risso JJ, Abraini JH: Ex vivo and in vivo neuroprotection induced by argon when given after an excitotoxic or ischemic insult. PLoS One 2012, 7(2):e30934.

5. Ryang YM, Fahlenkamp AV, Rossaint R, Wesp D, Loetscher PD, Beyer C, Coburn M: Neuroprotective effects of argon in an in vivo model of transient middle cerebral artery occlusion in rats. Crit Care Med 2011, 39(6):1448-1453.

6. Quillin ML, Breyer WA, Griswold IJ, Matthews BW: Size versus polarizability in protein-ligand interactions: binding of noble gases within engineered cavities in phage T4 lysozyme. J Mol Biol 2000, 302(4):955-977.

7. Fahlenkamp AV, Rossaint R, Haase H, Al Kassam H, Ryang YM, Beyer C, Coburn M: The noble gas argon modifies extracellular signal-regulated kinase 1/2 signaling in neurons and glial cells. Eur $\mathrm{J}$ Pharmacol 2012, 674(2-3):104-111.

8. Ulbrich F, Kaufmann KB, Coburn M, Lagreze WA, Roesslein M, Biermann J, Buerkle H, Loop T, Goebel U: Neuroprotective effects of Argon are mediated via an ERK-1/2 dependent regulation of hemeoxygenase-1 in retinal ganglion cells. J Neurochem 2015.

9. David HN, Haelewyn B, Risso JJ, Abraini JH: Modulation by the noble gas argon of the catalytic and thrombolytic efficiency of tissue plasminogen activator. Naunyn Schmiedebergs Arch Pharmacol 2013, 386(1):91-95.

10. Fahlenkamp AV, Coburn M, de Prada A, Gereitzig N, Beyer C, Haase H, Rossaint R, Gempt J, Ryang YM: Expression analysis following argon treatment in an in vivo model of transient middle cerebral 
artery occlusion in rats. Med Gas Res 2014, 4:11.

11. Dixon CE, Clifton GL, Lighthall JW, Yaghmai AA, Hayes RL: A controlled cortical impact model of traumatic brain injury in the rat. J Neurosci Methods 1991, 39(3):253-262.

12. Lighthall JW: Controlled cortical impact: a new experimental brain injury model. J Neurotrauma 1988, 5(1):1-15.

13. Krieg SM, Sonanini S, Plesnila N, Trabold R: Effect of small molecule vasopressin V1a and V2 receptor antagonists on brain edema formation and secondary brain damage following traumatic brain injury in mice. J Neurotrauma 2015, 32(4):221-227.

14. Krieg SM, Trabold R, Plesnila N: Time-Dependent Effects of Arginine-Vasopressin V1 Receptor Inhibition on Secondary Brain Damage after Traumatic Brain Injury. J Neurotrauma 2017, 34(7):1329-1336.

15. Bederson JB, Pitts LH, Tsuji M, Nishimura MC, Davis RL, Bartkowski H: Rat middle cerebral artery occlusion: evaluation of the model and development of a neurologic examination. Stroke 1986, $17(3): 472-476$.

16. Dixon CE, Lyeth BG, Povlishock JT, Findling RL, Hamm RJ, Marmarou A, Young HF, Hayes RL: A fluid percussion model of experimental brain injury in the rat. J Neurosurg 1987, 67(1):110-119.

17. Thomale U-WN: Evaluation des tierexperimentellen Modells einer traumatischen kortikalen Kontusion (Controlled Cortical Impact Injury) für Therapiestudien. Medizinische Fakultät - Universitätsklinikum Charité; 2001.

18. Jawad N, Rizvi M, Gu J, Adeyi O, Tao G, Maze M, Ma D: Neuroprotection (and lack of neuroprotection) afforded by a series of noble gases in an in vitro model of neuronal injury. Neurosci Lett 2009, 460(3):232-236.

19. Zhuang L, Yang T, Zhao H, Fidalgo AR, Vizcaychipi MP, Sanders RD, Yu B, Takata M, Johnson MR, Ma $\mathrm{D}$ : The protective profile of argon, helium, and xenon in a model of neonatal asphyxia in rats. Crit Care Med 2012, 40(6):1724-1730.

20. Spaggiari S, Kepp O, Rello-Varona S, Chaba K, Adjemian S, Pype J, Galluzzi L, Lemaire M, Kroemer G: Antiapoptotic activity of argon and xenon. Cell Cycle 2013, 12(16):2636-2642.

21. Ulbrich F, Kaufmann K, Roesslein M, Wellner F, Auwärter V, Kempf J, Loop T, Buerkle H, Goebel U: Argon Mediates Anti-Apoptotic Signaling and Neuroprotection via Inhibition of Toll-Like Receptor 2 and 4. PLOS ONE 2015, 10(12):e0143887.

22. Rothman SM, Olney JW: Glutamate and the pathophysiology of hypoxic-ischemic brain damage. Ann Neurol 1986, 19(2):105-111.

23. Harris K, Armstrong SP, Campos-Pires R, Kiru L, Franks NP, Dickinson R: Neuroprotection against traumatic brain injury by xenon, but not argon, is mediated by inhibition at the N-methyl-D-aspartate receptor glycine site. Anesthesiology 2013, 119(5):1137-1148.

24. Brucken A, Kurnaz P, Bleilevens C, Derwall M, Weis J, Nolte K, Rossaint R, Fries M: Dose dependent neuroprotection of the noble gas argon after cardiac arrest in rats is not mediated by K(ATP)-channel opening. Resuscitation 2014, 85(6):826-832. 
25. Abraini JH, Kriem B, Balon N, Rostain JC, Risso JJ: Gamma-aminobutyric acid neuropharmacological investigations on narcosis produced by nitrogen, argon, or nitrous oxide. Anesth Analg 2003, 96(3):746-749, table of contents.

26. Ulbrich F, Lerach T, Biermann J, Kaufmann KB, Lagreze WA, Buerkle H, Loop T, Goebel U: Argon mediates protection by interleukin-8 suppression via a TLR2/TLR4/STAT3/NF-kappaB pathway in a model of apoptosis in neuroblastoma cells in vitro and following ischemia-reperfusion injury in rat retina in vivo. $J$ Neurochem 2016, 138(6):859-873.

\section{Figures}
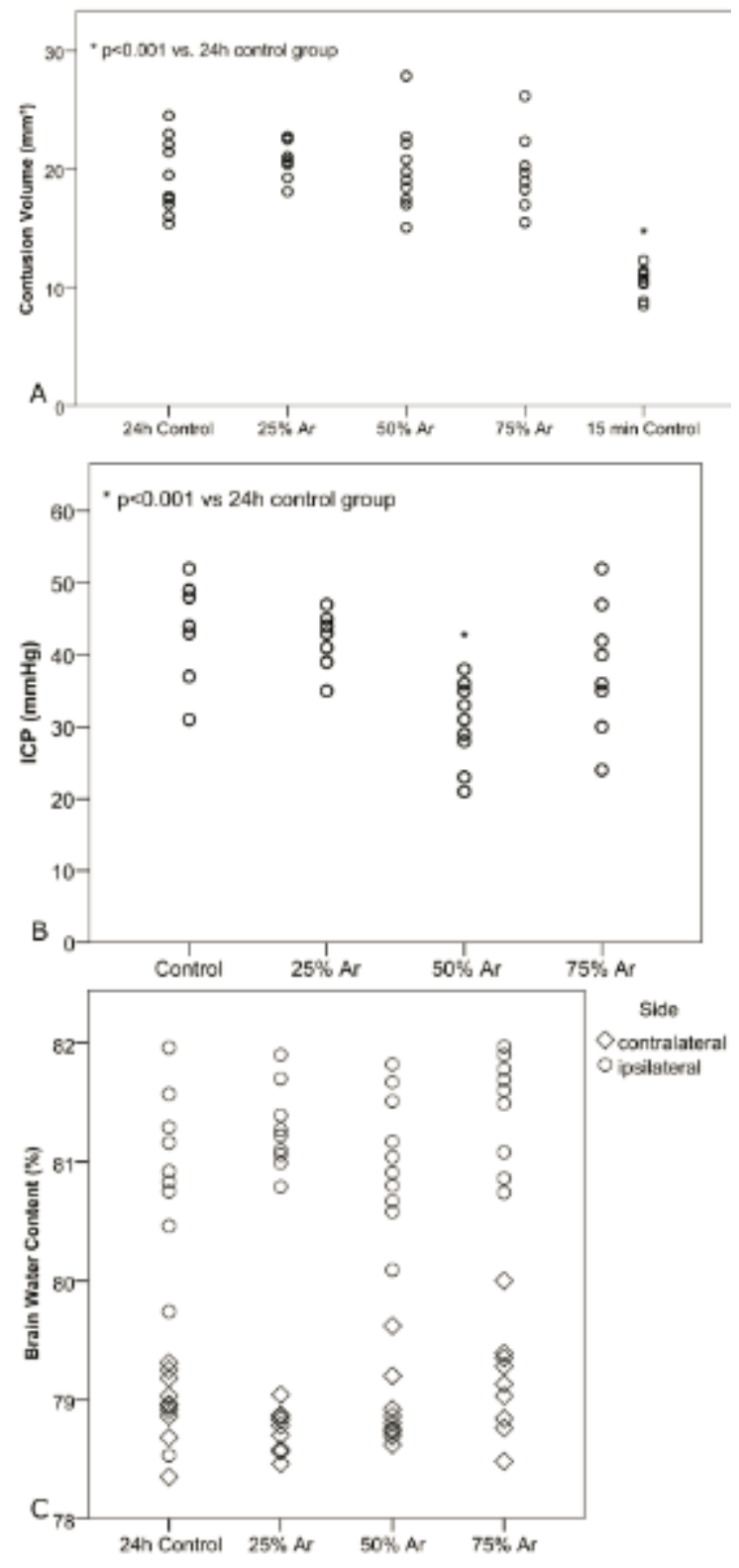

Figure 1 
Treatment was administered 30 min before trauma until $4 \mathrm{~h}$ after trauma A: Contusion volumes for the 15 min and $24 \mathrm{~h}$ control groups and the animals treated with argon. B: Intracranial pressure (ICP) values 24 $\mathrm{h}$ after TBI. C: Brain water content (BWC) values of each hemisphere $24 \mathrm{~h}$ after TBI, divided by groups.

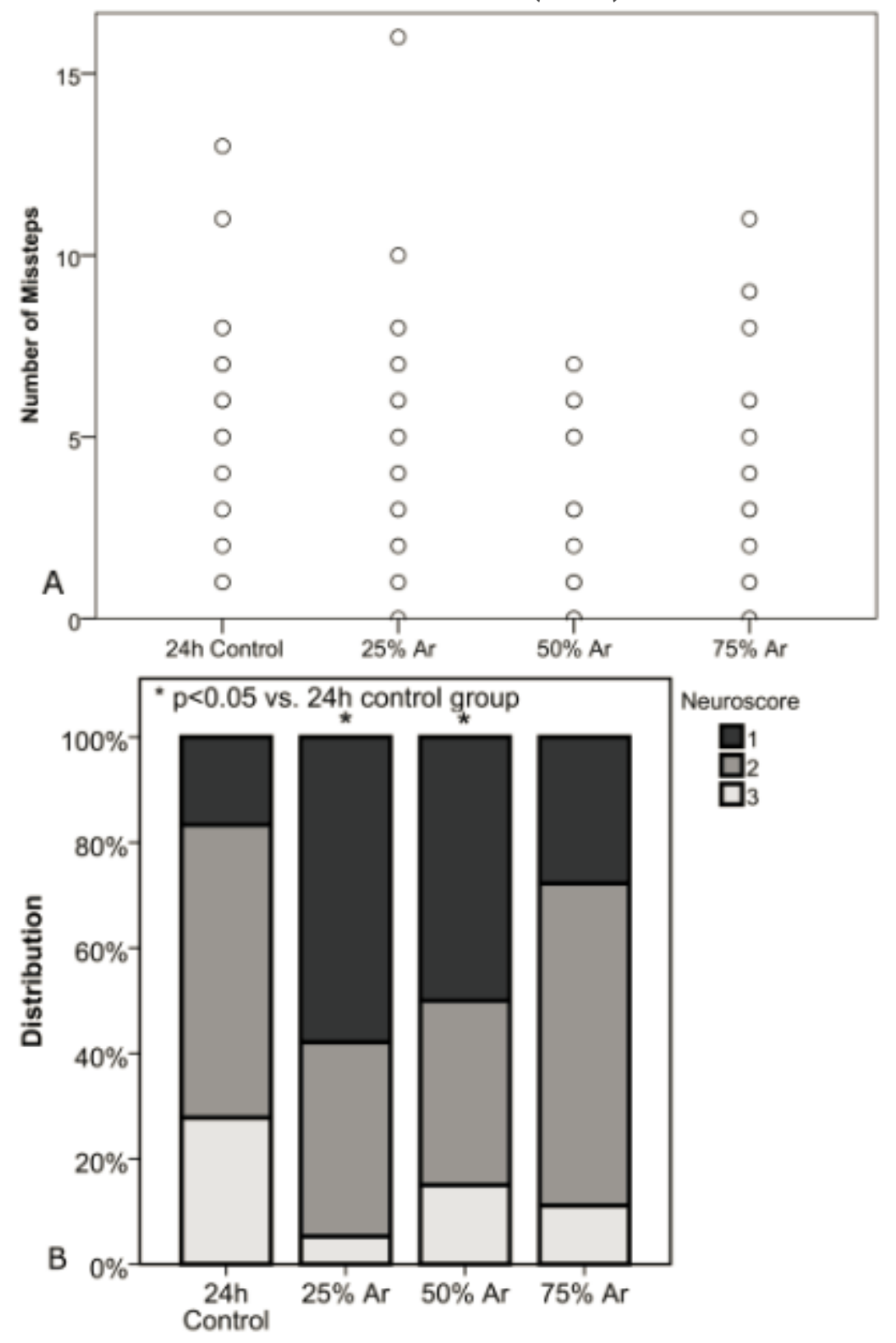

Figure 2

Treatment was administered 30 min before trauma until $4 \mathrm{~h}$ after trauma A: Total number of beamwalk missteps $24 \mathrm{~h}$ after trauma. B: Dixon's and Bederson's neuroscores $24 \mathrm{~h}$ after trauma. 


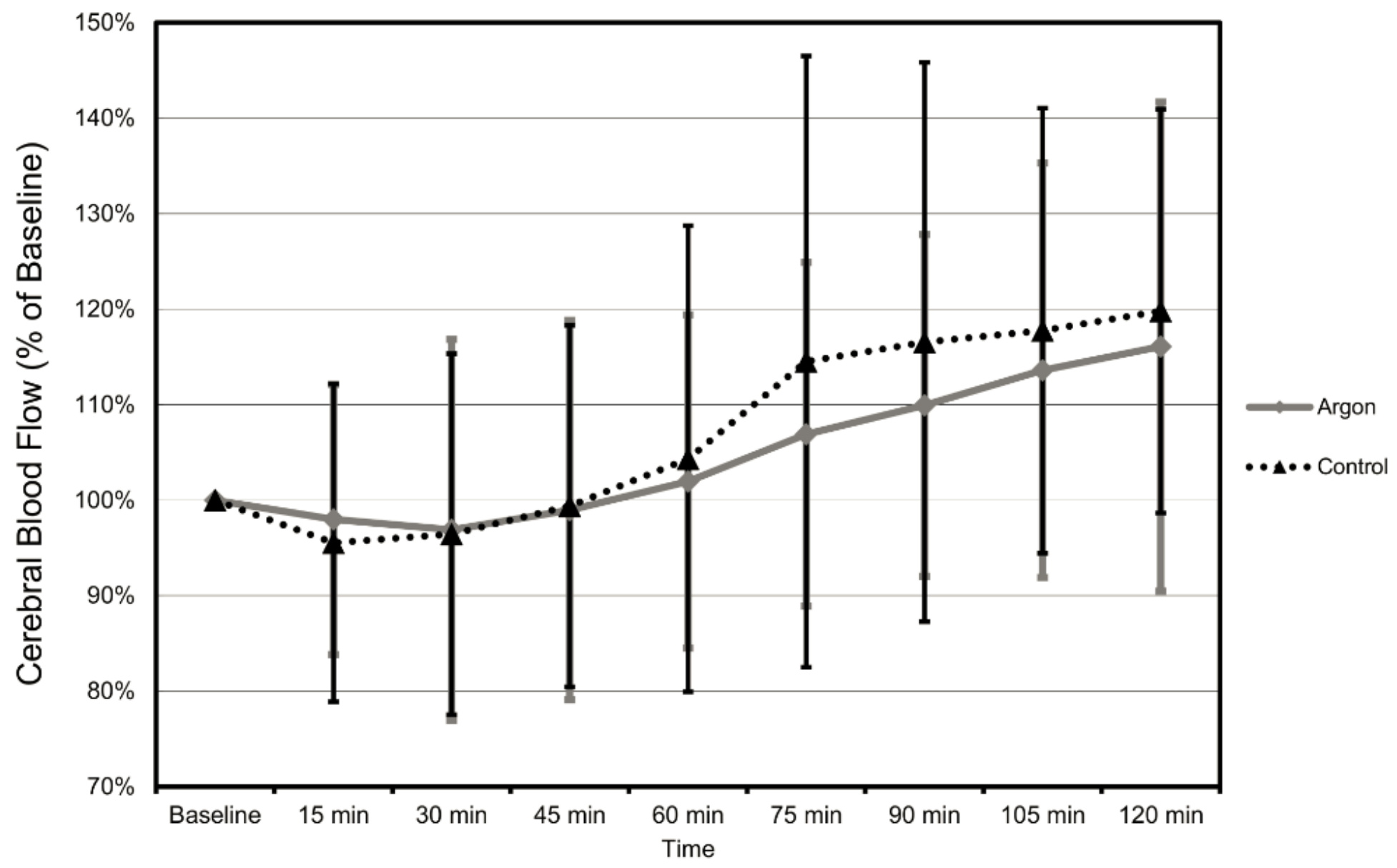

Figure 3

$\mathrm{CBF}$ values in time course $2 \mathrm{~h}$ after trauma in $15 \mathrm{~min}$ intervals. All values in relation to baseline $30 \mathrm{~min}$ prior to trauma. Therapy was administered $2 \mathrm{~h}$ after trauma. 


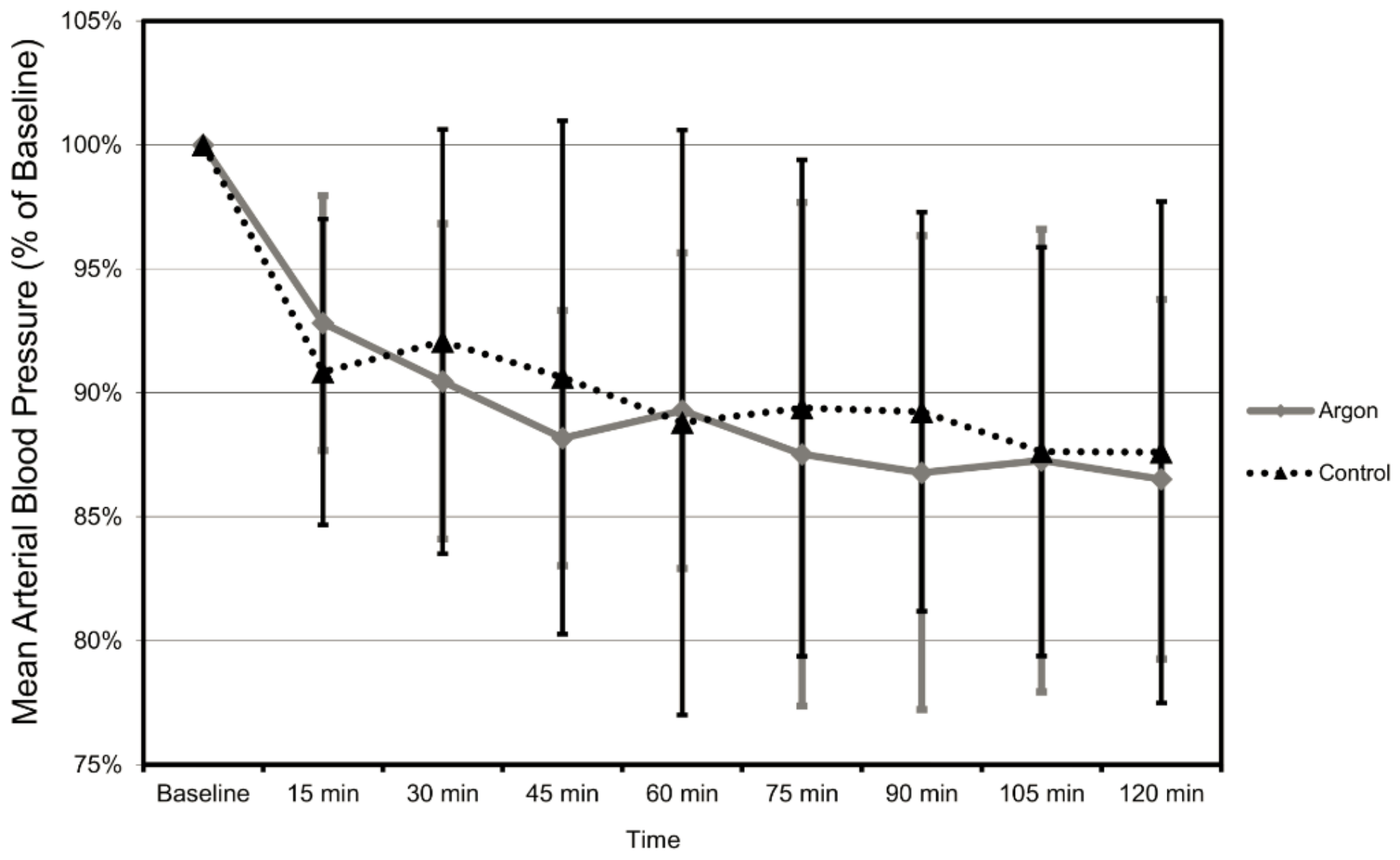

Figure 4

Mean arterial blood pressure (MAP) values in time course $2 \mathrm{~h}$ after trauma in $15 \mathrm{~min}$ intervals. All values in relation to baseline 30 min prior to trauma. Therapy was administered $2 \mathrm{~h}$ after trauma.

\section{Supplementary Files}

This is a list of supplementary files associated with this preprint. Click to download.

- BMCAuthorChecklistFull.pdf 